Lorenz Keim • Rainer Brandner

\title{
Facies interfingering and synsedimentary tectonics on late Ladinian-early Carnian carbonate platforms (Dolomites, Italy)
}

Published online: 15 February 2002

(C) Springer-Verlag 2002

\section{Int J Earth Sciences (Geol Rundsch) (2001) DOI s005310000192}

Figures 4, 5, 6 were given incorrect and are reproduced correctly here.
The online version of the original article can be found at http://dx.doi.org/10.1007/s005310000192

\section{Keim $(-$ R. Brandner}

Institut für Geologie und Paläontologie, Universität Innsbruck, Innrain 52, 6020 Innsbruck, Austria

e-mail: lorenz.keim@uibk.ac.at

Fax: 512-5072914

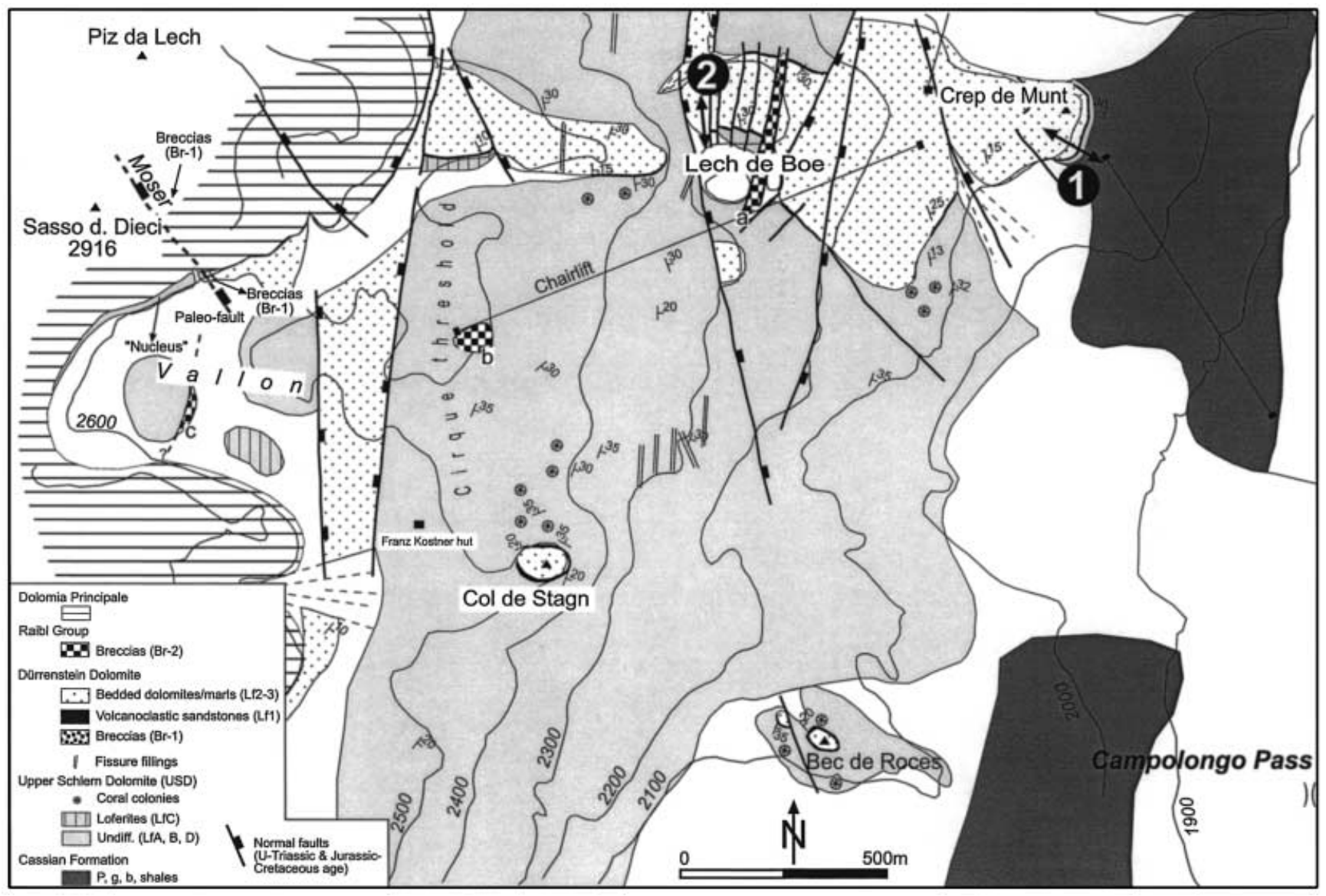

Fig. 4 Geological map from the east flank of the Sella, modified after Reithofer (1928). Note the abundant fissure fillings and extensional faults. Numbers 1 and 2 refer to measured sections (see Fig. 6) 
Fig. 5 Cross section at the Sella eastern side. The breccias (Br-1) onlapping the 'nucleus' are related to extensional tectonics (open arrow) at the LadinianCarnian boundary. The Norian Dolomia Principale is sealing this normal fault. The other faults (black arrows), displacing also the Dolomia Principale, are younger and may be interpreted as Late Triassic synsedimentary normal faults in connection with the overall Mesozoic extensional tectonics (Doglioni 1992). Stippled lines are interpretative bedding patterns. Numbers 1 and 2 refer to stratigraphic sections (see Fig. 6)

Fig. 6 Stratigraphic section at Ciavaces, Piccolo Pordoi, Lech de Boè and Crep de Munt (for locations see Figs. 1 and 4). Stippled lines are proposed lithostratigraphic correlations. Note the presence of hummocky cross lamination (hcl, section 1) within the Cassian Formation and the basal Dürrenstein Dolomite (Lf1) at Crep de Munt indicating storm deposition on a shoreface probably not deeper than $20 \mathrm{~m}$ water depth. The subtidal facies of the Dürrenstein Dolomite (Lf2, sections 1 and 2) is almost wedging out towards section 3. There is a facies interfingering between Schlernplateau beds at Ciavaces (section 4) and Dürrenstein Dolomite at Piccolo Pordoi. USD Upper Schlern Dolomite, $T V$ Travenanzes Fm., DP Dolomia Principale. See text for discussion

\section{Vallon}

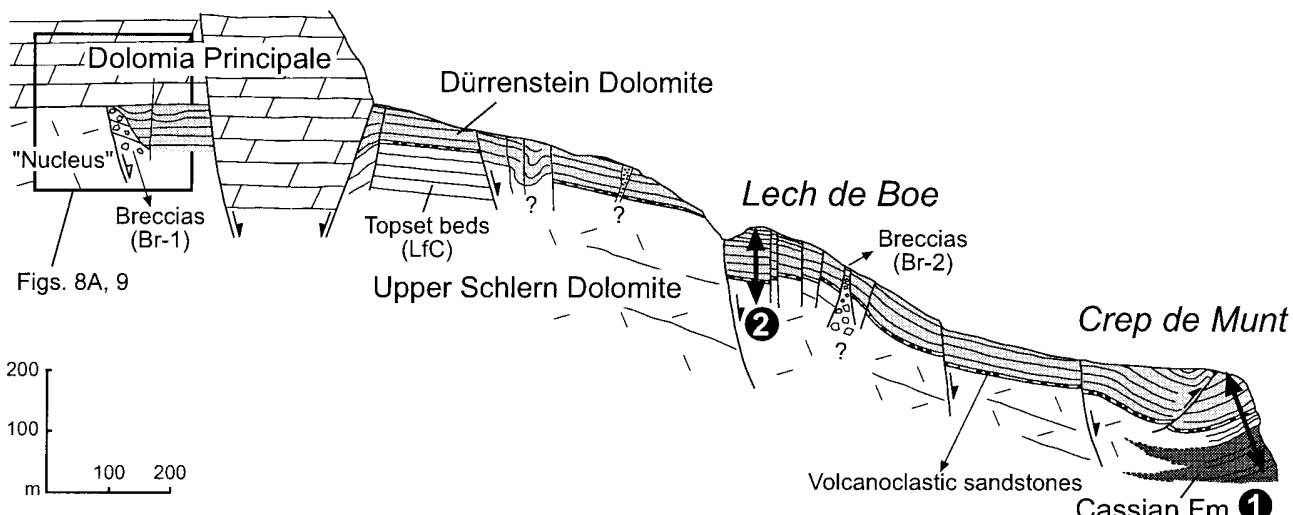

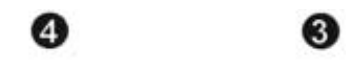

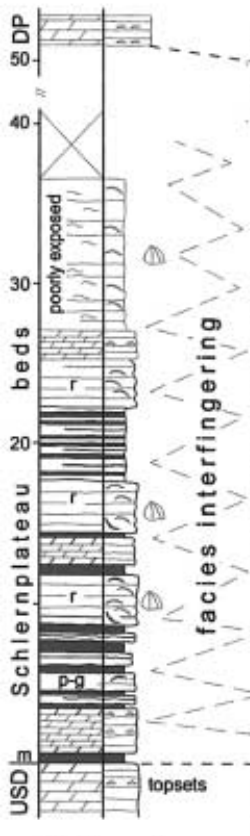

Platform top Clavaces

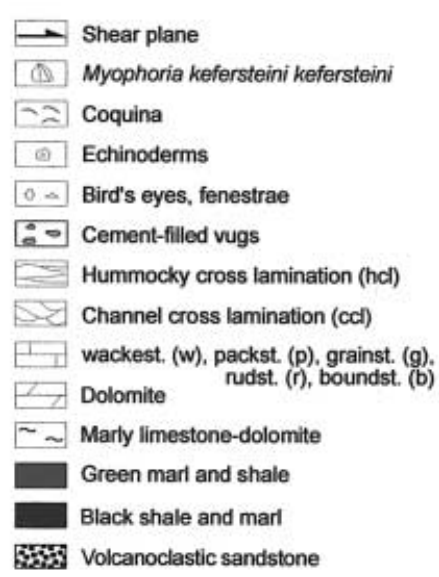

(3) 2

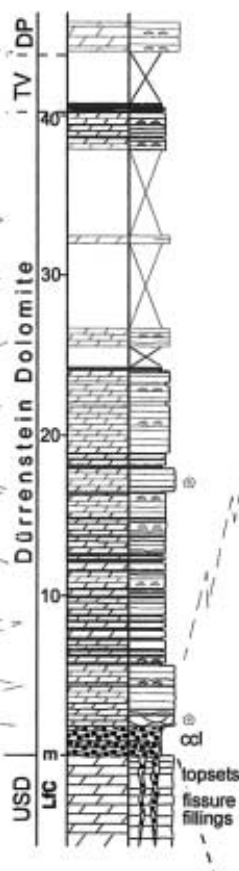

Platform top Piccolo Pordo

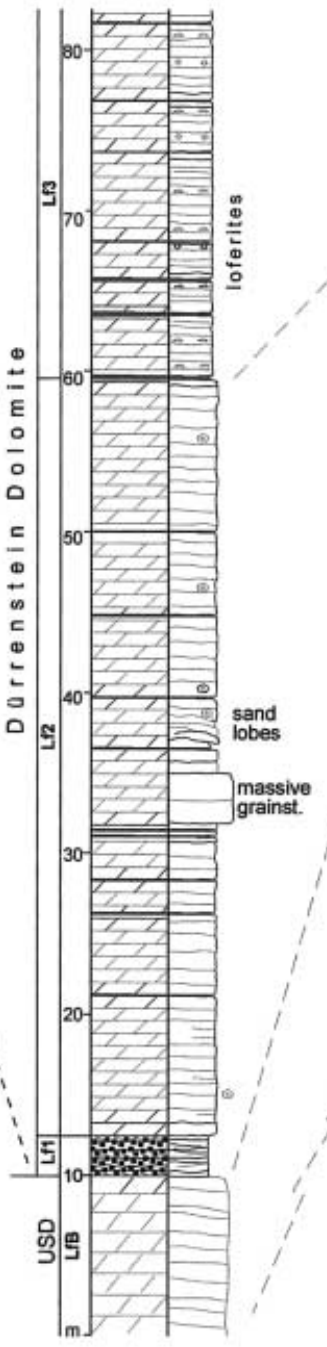

gently dipping slope Lech de Boe 